\title{
Interlaboratory consensus building challenge
}

\author{
Antonio Possolo ${ }^{1}$
}

Published online: 5 March 2020

(C) This is a U.S. government work and not under copyright protection in the U.S.; foreign copyright protection may apply 2020

We would like to invite you to participate in the Analytical Challenge, a series of puzzles to entertain and challenge our readers. This special feature of "Analytical and Bioanalytical Chemistry" has established itself as a truly unique quiz series, with a new scientific puzzle published every three months. Readers can access the complete collection of published problems with their solutions on the ABC homepage at http://www.springer.com/abc. Test your knowledge and tease your wits in diverse areas of analytical and bioanalytical chemistry by viewing this collection.

In the present challenge, interlaboratory comparisons is the topic. And please note that there is a prize to be won (a Springer book of your choice up to a value of $€ 100$ ). Please read on...

\section{Meet the challenge}

Figure 1 depicts measurement results for the activity of iron-59 from an interlaboratory comparison which started in 1976 and has involved many national metrology institutes [3]. These are measurements of equivalent activity made using the International Reference System (Système International de Référence, SIR) that is maintained at the International Bureau of Weights And Measures (BIPM) [4]. This measurement system compares the activity of iron-59 in a solution submitted by a participant with the activity of several well-characterized radium-226 reference sources. The equivalent activity, $A_{\mathrm{e}}\left({ }^{59} \mathrm{Fe}\right)$, is defined as that activity which will produce an electrical current in the ionization chamber equal to the current produced by the radium reference source of the highest activity.

Antonio Possolo

antonio.possolo@nist.gov

1 National Institute of Standards and Technology (NIST), 100 Bureau Drive, Gaithersburg, MD 20899-8980, USA

\section{The challenge}

Interlaboratory comparisons form an essential part of metrology and they are organized to assess the ability of laboratories to provide accurate measurement results. For this, one needs to compute a single consensus value that represents a collective estimate of the quantity being measured.

The challenge before us comprises four tasks:

1. deriving a consensus value from these results;

2. evaluating the associated standard uncertainty;

3. producing a coverage interval that, with $95 \%$ confidence, is believed to include the true value of which the consensus value is an estimate;

4. suggesting how the measurement result from NIST may be compared with the consensus value.

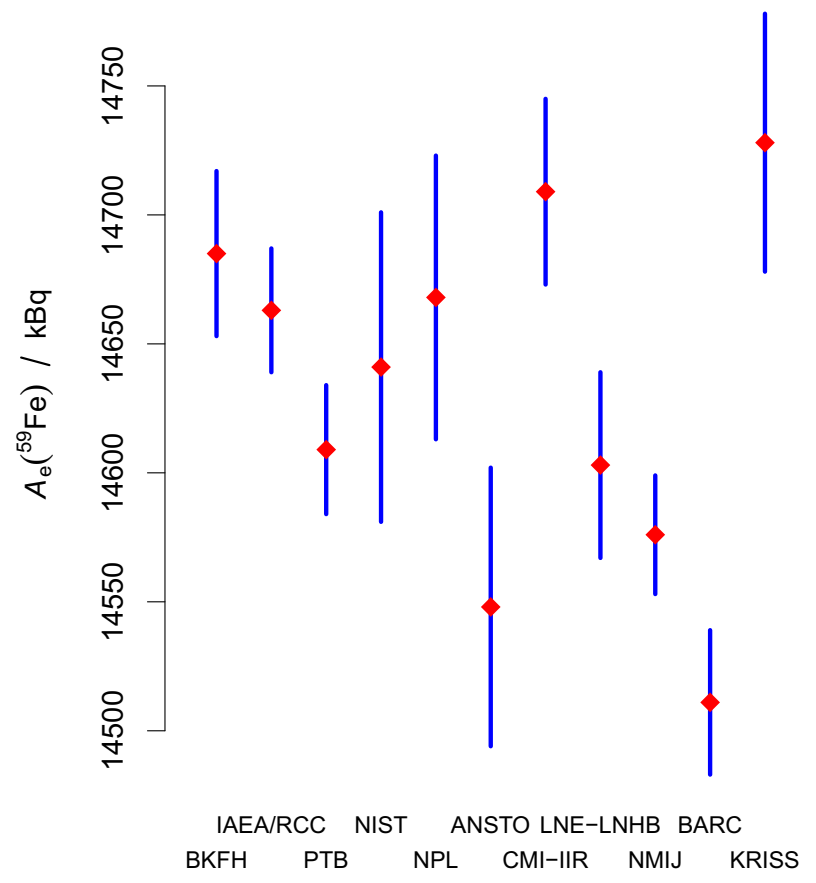

Fig. 1 Selected measured values for the activity of iron-59 obtained in key comparison BIPM.RI(II)-K1.Fe-59 [3]. The red diamonds represent the most recent result produced by each participant and vertical blue lines represent the associated standard uncertainties 
Table 1 Selected measurement results for the activity of iron-59 obtained in key comparison BIPM.RI(II)-K1.Fe-59

\begin{tabular}{llll}
\hline Lab & Year & $A_{\mathrm{e}}\left({ }^{59} \mathrm{Fe}\right)$ & $u\left(A_{\mathrm{e}}\left({ }^{59} \mathrm{Fe}\right)\right)$ \\
\hline BKFH & 2001 & $14,685 \mathrm{kBq}$ & $32 \mathrm{kBq}$ \\
IAEA/RCC & 1978 & $14,663 \mathrm{kBq}$ & $24 \mathrm{kBq}$ \\
PTB & 2012 & $14,609 \mathrm{kBq}$ & $25 \mathrm{kBq}$ \\
NIST & 2001 & $14,641 \mathrm{kBq}$ & $60 \mathrm{kBq}$ \\
NPL & 1979 & $14,668 \mathrm{kBq}$ & $55 \mathrm{kBq}$ \\
ANSTO & 1980 & $14,548 \mathrm{kBq}$ & $54 \mathrm{kBq}$ \\
CMI-IIR & 1984 & $14,709 \mathrm{kBq}$ & $36 \mathrm{kBq}$ \\
LNE-LNHB & 2013 & $14,603 \mathrm{kBq}$ & $36 \mathrm{kBq}$ \\
NMIJ & 2014 & $14,576 \mathrm{kBq}$ & $23 \mathrm{kBq}$ \\
BARC & 1998 & $14,511 \mathrm{kBq}$ & $28 \mathrm{kBq}$ \\
KRISS & 1999 & $14,728 \mathrm{kBq}$ & $50 \mathrm{kBq}$ \\
\hline
\end{tabular}

Table 1 lists the measurement results shown in Fig. 1.

There are many reasonable, alternative solutions for this challenge, and the criteria also are plural that may be used to gauge their relative merit. A good solution will explain the conditions that validate it and offer evidence to the effect that these particular measurement results do indeed meet these conditions.

Take the consensus value, as an example. The alternative methods to compute it range from a simple arithmetic average or median that both ignore the reported uncertainties, to the elaborate hierarchical Bayesian procedure that takes into account not only the uncertainties provided by the individual laboratories but also the spread between these values [2]. Similarly, the solution for step 4 may be the so-called degree of equivalence [1], or it may be arrived at by following a less traveled road.

\section{References}

1. Comité International des Poids et Mesures (CIPM): Mutual recognition of national measurement standards and of calibration and measurement certificates issued by national metrology institutes. Bureau International des Poids et Mesures (BIPM), Pavillon de Breteuil, Sèvres, France (1999). www.bipm.org/en/ cipm-mra/ Technical Supplement revised in October 2003.

2. Koepke A, Lafarge T, Possolo A, Toman B. Consensus building for interlaboratory studies, key comparisons, and meta-analysis. Metrologia. 2017;54(3):S34-S62. https://doi.org/10.1088/1681-7575/aa6c0e.

3. Michotte C, Ratel G, Courte S, Kossert K, Nähle O, Dersch R, Branger T, Bobin C, Yunoki A, Sato Y. BIPM comparison BIPM.RI(II)-K1.Fe-59 of activity measurements of the radionuclide 59Fe for the PTB (Germany), LNE-LNHB (France) and the NMIJ (Japan), and the linked APMP.RI(II)-K2.Fe-59 comparison. Metrologia. 2020;57(1A):06003. https://doi.org/10. 1088/0026-1394/57/1a/06003.

4. Ratel G. The système international de référence and its application in key comparisons. Metrologia. 2007;44:S7-S16. https://doi.org/10.1088/0026-1394/44/4/S02.

We invite our readers to participate in the Analytical Challenge by solving the puzzle above. Please send the correct solution to abc-challenge@ springer.com by October 1, 2020. Make sure you enter "Interlaboratory consensus building challenge" in the subject line of your e-mail. The winner will be notified by e-mail and his/her name will be published on the "Analytical and Bioanalytical Chemistry" homepage at http://www.springer.com/abc and in the journal (volume 413/issue 01) where readers will find the solution and a short explanation.

The next Analytical Challenge will be published in 412/25, October 2020. If you have enjoyed solving this Analytical Challenge you are invited to try the previous puzzles on the ABC homepage.

Publisher's note Springer Nature remains neutral with regard to jurisdictional claims in published maps and institutional affiliations. 